\title{
BMJ Open Prevalence of comorbidities and their associated factors in patients with type 2 diabetes at a tertiary care department in Ningbo, China: a cross-sectional study
}

\author{
Xueyu Li, ${ }^{1,2}$ Kaushik Chattopadhyay (D) , ${ }^{3}$ Shengnan $\mathrm{Xu},{ }^{2}$ Yanshu Chen, ${ }^{2}$ Miao Xu, ${ }^{2}$ \\ Li Li (D) , ${ }^{2}$ Jialin Li (1) ${ }^{2}$
}

To cite: Li X, Chattopadhyay K, $\mathrm{Xu}$ S, et al. Prevalence of comorbidities and their associated factors in patients with type 2 diabetes at a tertiary care department in Ningbo, China: a crosssectional study. BMJ Open 2021;11:e040532. doi:10.1136/ bmjopen-2020-040532

- Prepublication history for this paper is available online. To view these files, please visit the journal online (http://dx.doi org/10.1136/bmjopen-2020040532).

$\mathrm{XL}$ and $\mathrm{KC}$ contributed equally.

Received 15 May 2020

Revised 25 November 2020

Accepted 02 December 2020

D) Check for updates

(c) Author(s) (or their employer(s)) 2021. Re-use permitted under CC BY-NC. No commercial re-use. See rights and permissions. Published by BMJ.

${ }^{1}$ School of Medicine, Ningbo University, Ningbo, China ${ }^{2}$ Department of Endocrinology and Metabolism, Ningbo First Hospital, Ningbo, China ${ }^{3}$ Division of Epidemiology and Public Health, School of Medicine, University of Nottingham, Nottingham, UK

Correspondence to Dr Jialin Li; lijialin@sina.com

\section{ABSTRACT}

Objectives To determine the prevalence of comorbidities in patients with type 2 diabetes mellitus (T2DM) and identify the factors independently associated with comorbidities in a tertiary care department in Ningbo, China.

Design A computerised medical records database was used to conduct a cross-sectional study.

Setting The study was conducted in a tertiary care department in Ningbo, China.

Participants The study was conducted on adult patients with T2DM, and it included 8 years of data, from 1 January 2012 to 31 December 2019.

The primary outcome measure Comorbidity was defined as the coexistence of at least one other chronic condition, that is, either a physical non-communicable disease (duration $\geq 3$ months), a mental health condition (duration $\geq 3$ months) or an infectious disease (duration $\geq 3$ months). Results In total, 4777 patients with T2DM satisfied the eligibility criteria. Over 8 years, the prevalence of comorbidities was $93.7 \%$. The odds of comorbidities increased with the age of patients (18 to 39 years: 1 ; 40 to 59 years: OR $2.80,95 \%$ Cl 1.98 to 3.96; 60 to 69 years: OR $4.43,95 \% \mathrm{Cl} 3.04$ to 6.44 ; and $\geq 70$ years: OR $10.97,95 \% \mathrm{Cl} 7.17$ to 16.77$)$. The odds were lower in female patients (OR $0.66,95 \% \mathrm{Cl} 0.51$ to 0.84 ), patients residing in rural areas (OR $0.75,95 \% \mathrm{Cl} 0.59$ to 0.95$)$ and patients without health insurance (OR $0.62,95 \% \mathrm{Cl} 0.46$ to 0.83 ). The odds were higher in single/divorced/widowed patients compared with those in married patients (OR 1.95, $95 \% \mathrm{Cl} 1.21$ to 3.12 ).

Conclusions A large percentage of patients with T2DM in the tertiary care department in Ningbo, China, had comorbidities, and the factors associated with comorbidities were identified. The findings could be used in developing, evaluating and implementing interventions aimed at improving outcomes in patients with T2DM with comorbidities.

\section{INTRODUCTION}

Ningbo is an economically developed Chinese city in Zhejiang Province. The population of the city is approximately 8.2 million. ${ }^{1}$ Non-communicable diseases are prevalent in the city, and one of the most prevalent non-communicable diseases is type 2 diabetes mellitus (T2DM), a complex
Strengths and limitations of this study

- Ours was the first study to investigate comorbidities in patients with type 2 diabetes in Ningbo and the broader Zhejiang Province of China.

- We included all the chronic conditions in our study; they were coded using the International Classification of Diseases, $10^{\text {th }}$ edition (ICD-10) in our database.

- Our study had extremely low missing data, and the multiple logistic regression analysis included a sample with missing data for the adjusted variable.

- As it was a cross-sectional study, the causal relationship between the variables and the comorbidities could not be determined.

- The high prevalence of comorbidities in our study could be due to the study setting (ie, hospital)

metabolic disorder. ${ }^{2}$ China has the largest T2DM epidemic in the world, and in Ningbo, its prevalence in adults $\geq 40$ years of age is $21 \% .^{3}$ In Ningbo, the diabetes-related mortality is 14.5 per 100000 population. ${ }^{4}$

There is no international consensus regarding the best way to define comorbidity. It is usually defined as the coexistence of other conditions with an index condition (ie, the main condition under study) where these other conditions are not consequences of the index condition. ${ }^{5-7}$ Comorbidities accelerate the progression of individual conditions, encourage the development of other physical and mental conditions and even lead to premature mortality. ${ }^{8-10}$ Moreover, they negatively affect overall health, wellbeing and functioning. ${ }^{11}{ }^{12}$ Additionally, they lead to high treatment burden, high healthcare utilisation and expenditure and loss of economic output. ${ }^{13} 14$ In real life, T2DM is rarely presented in isolation and is always accompanied by comorbidity. ${ }^{15} 16$ 
To date, no study has been undertaken to investigate comorbidities in patients with T2DM in Ningbo. The study objectives were to determine the prevalence of comorbidities in patients with T2DM and identify the factors independently associated with comorbidities. This knowledge could be used in developing, evaluating and implementing interventions aimed at improving outcomes in patients with T2DM with comorbidities.

\section{METHODS}

\section{Study location, study design, data source and study period}

We conducted the study in a tertiary care department, the Department of Endocrinology and Metabolism, Ningbo First Hospital, in Ningbo, China. This tertiary care hospital delivers speciality healthcare services, provides medical education and conducts research. ${ }^{17}{ }^{18}$ Locals and people from the surrounding areas visit this hospital as no referral is required from the general practitioner. ${ }^{17}$ An existing computerised medical records database was used for conducting this cross-sectional study. This database contained information on all inpatients. Since it was a real-time database, new patients were added continuously. Data were entered by the medico-nursing team, and an independent group of the hospital staff was responsible for assessing the quality of the data and overall database management. All the conditions were coded using the International Classification of Diseases, $10^{\text {th }}$ edition (ICD-10). This retrospective study included 8 years of data, from 1 January 2012 to 31 December 2019, and the information was available on 6755 patients.

\section{Study population and study inclusion and exclusion criteria}

Adult patients ( $\geq 18$ years) with T2DM were included. If a patient was admitted more than once during the study period, data pertinent to the last admission were extracted to obtain the most recent information on health conditions. Individuals with gestational diabetes, type 1 diabetes, secondary diabetes and unknown types of diabetes were excluded.

\section{Study variables}

We extracted and categorised the following information from the database:

- age (18 to 39 years, 40 to 59 years, 60 to 69 years or $\geq 70$ years $)$,

- $\operatorname{sex}$ (male or female),

- education (university/college, class 7 to 12, class 1 to 6 or no qualification),

- occupation (manual worker (ie, more physical work than mental work), non-manual worker (ie, more mental work than physical work) or never worked/ retired),

- marital status (married or single/divorced/widowed),

- residence (urban or rural using the 'hukou' system that is, the Chinese household registration system),

- health insurance,

- smoking (current status),
- alcohol consumption (current status),

- duration of T2DM ( $\leq 1$ year, $>1$ to 5 years, $>5$ to 10 years or $>10$ years) and

- blood glucose level (glycated haemoglobin (HbA1c $<7 \%$ (good) or $\geq 7 \%$ (poor)), estimated using the high-performance liquid chromatographic method and D-10 Haemoglobin Analyser (Bio-Rad, USA)). In China, the recommended HbA1c treatment target did not change over the study period $(<7 \%$ for most patients with T2DM) ${ }^{19-21}$

In addition, information on comorbidities was extracted. The index condition was T2DM. Comorbidity was defined as the coexistence of at least one other chronic condition, that is, either a physical noncommunicable disease (duration $\geq 3$ months), a mental health condition (duration $\geq 3$ months) or an infectious disease (duration $\geq 3$ months). ${ }^{5-7}$ T2DM-specific complications (ie, microvascular complications, such as diabetic retinopathy, nephropathy and neuropathy/foot) were excluded as these were consequences of the index condition; hence, they were not considered as comorbidities. ${ }^{6}$

The researchers had no access to information that could identify individual patients during data analyses. No informed consent was required as per the research ethics rules.

\section{Patient and public involvement}

Patients and the public were not involved in the study.

\section{Statistical analyses}

We calculated numbers and percentages for categorical variables and means and SDs for normally distributed continuous variables. We used simple logistic regression method to investigate the association between the different variables and the comorbidities. We developed a multiple logistic regression model to identify any independent associations. For this, we used backward stepwise regression analysis and included all the variables. Additionally, we performed a sensitivity analysis-in the multiple logistic regression model, we included only those variables that had a $p$ value $\leq 0.20$ in simple logistic regressions. We calculated ORs and 95\% CIs. We used IBM SPSS Statistics V.26.0 for Windows for statistical analyses.

\section{RESULTS}

A total of 4777 patients with T2DM satisfied the eligibility criteria. The mean $( \pm \mathrm{SD})$ age of patients was $64.2( \pm 14.2)$ years, and approximately $52 \%(\mathrm{n}=2482)$ of them were men. The mean $( \pm \mathrm{SD})$ HbAlc level was $9.2 \%( \pm 2.4 \%)$. Over 8 years, the prevalence of comorbidities was $93.7 \%$. The year-wise prevalences from 2012 to 2019 were $96.9 \%, 95.0 \%$, $92.9 \%, 95.5 \%, 93.2 \%, 91.5 \%, 94.0 \%$ and $93.6 \%$, respectively.

Figure 1 shows the number of comorbidities in our study. The mean $( \pm \mathrm{SD})$ number of comorbidities was 3 $( \pm 1)$. Figure 2 shows the percentage of comorbidities in our study in the different age groups. In the $\geq 70$ years age group, $68.5 \%$ (1247) had $\geq 3$ comorbidities, whereas 


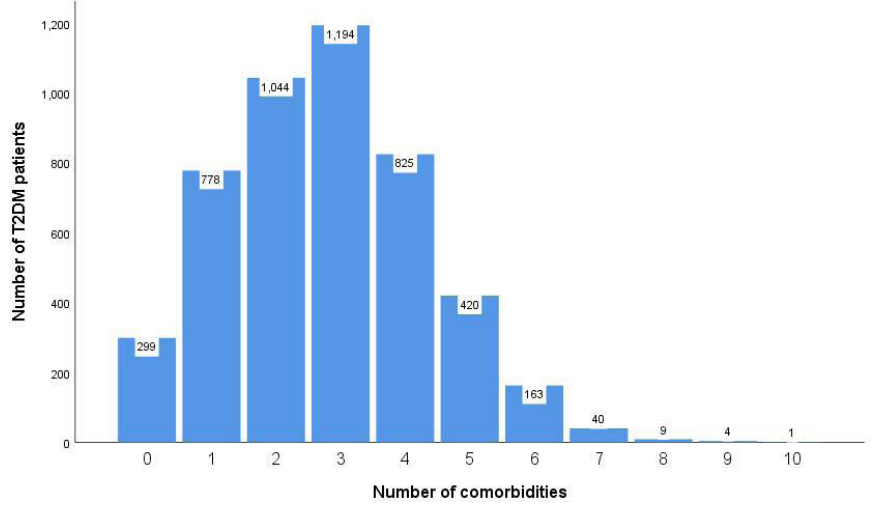

Figure 1 Number of comorbidities in our study. T2DM, type 2 diabetes mellitus.

the prevalences were only $33.1 \%$ (102), $43.5 \%$ (592) and $55.5 \%$ (715) in the 18 to 39,40 to 59 and 60 to 69 years age groups, respectively. Table 1 reports the most common comorbidities in our study. Essential hypertension $(49.4 \%)$, disorders of lipoprotein metabolism and other lipidaemias $(33.7 \%)$, non-toxic thyroid nodule $(22.8 \%)$, fatty change of liver $(20.6 \%)$ and cataract $(10.7 \%)$ were the five most prevalent comorbidities.

Table 2 reports the characteristics of the study participants. We found that the comorbidities were associated with age, sex, education, occupation, marital status, residence, health insurance and the duration of T2DM. Table 3 reports the multiple backward stepwise logistic regression analysis for determining factors independently associated with the comorbidities. The odds of comorbidities increased with the age of patients (18 to 39 years: 1; 40 to 59 years: OR $2.80,95 \%$ CI 1.98 to 3.96 ; 60 to 69 years: OR $4.43,95 \%$ CI 3.04 to 6.44 ; and $\geq 70$ years: OR $10.97,95 \%$ CI 7.17 to 16.77$)$. The odds were lower in female patients (OR $0.66,95 \%$ CI 0.51 to 0.84 ), patients residing in rural areas (OR $0.75,95 \%$ CI 0.59 to 0.95 ) and patients without health insurance (OR $0.62,95 \%$ CI 0.46 to 0.83$)$. The odds were higher in single/divorced/ widowed patients compared with married patients (OR $1.95,95 \%$ CI 1.21 to 3.12 ). We obtained similar results in the sensitivity analysis.

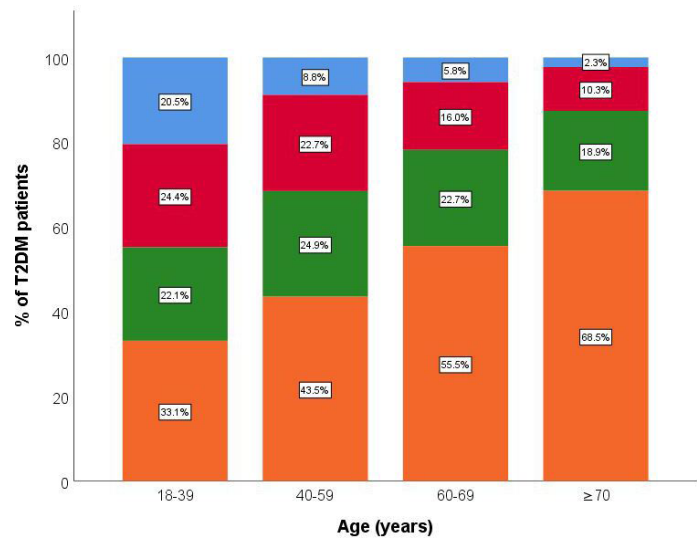

No comorbidity 1 comorbidity
2 comorbidities $\geq 3$ comorbidities

Figure 2 Percentage of comorbidities in our study in the different age groups. T2DM, type 2 diabetes mellitus.
Table 1 Most common comorbidities in our study

\begin{tabular}{ll}
\hline $\begin{array}{l}\text { Most common comorbidities (based on } \\
\text { ICD-10 classification) }\end{array}$ & $\begin{array}{l}\text { Patients with } \\
\text { T2DM } \\
\text { n (\%) }\end{array}$ \\
\hline $\begin{array}{l}\text { Essential hypertension (I10) } \\
\text { Disorders of lipoprotein metabolism and } \\
\text { other lipidaemias (E78) }\end{array}$ & $2362(49.4)$ \\
\hline $\begin{array}{l}\text { Non-toxic thyroid nodule (E04) } \\
\text { Fatty (change of) liver (K76) }\end{array}$ & $1088(22.8)$ \\
\hline Cataract (H26) & $984(20.6)$ \\
\hline Chronic ischaemic heart disease (I25) & $512(10.7)$ \\
\hline Atherosclerosis (170) & $455(9.5)$ \\
\hline Osteoporosis (M81) & $411(8.6)$ \\
\hline Cerebral infarction (I63) & $348(7.3)$ \\
\hline Benign prostatic hyperplasia (N40) & $341(7.1)$ \\
\hline $\begin{array}{l}\text { Abnormal findings on diagnostic imaging of } \\
\text { lung (R91) }\end{array}$ & $287\left(12.2^{*}\right)$ \\
\hline $\begin{array}{l}\text { Thoracic, thoracolumbar and lumbosacral } \\
\text { intervertebral disc disorders (M51) }\end{array}$ & $260(5.4)$ \\
\hline Obesity (E66) & $177(3.7)$ \\
\hline Cervical disc disorders (M50) & $161(3.4)$ \\
\hline $\begin{array}{l}\text { Chronic viral hepatitis (B18) } \\
\text { Sleep disorders (G47) }\end{array}$ & $138(2.9)$ \\
\hline $\begin{array}{l}\text { Gout (M10) } \\
\text { Disorders of purine and pyrimidine } \\
\text { metabolism (E79) }\end{array}$ & $135(2.8)$ \\
\hline Atrial fibrillation and flutter (I48) & $132(2.8)$ \\
\hline Gastro-oesophageal reflux disease (K21) & $111(2.7)$ \\
\hline
\end{tabular}

*In 2482 men.

ICD-10, International Classification of Diseases, $10^{\text {th }}$ edition; T2DM, type 2 diabetes mellitus.

\section{DISCUSSION}

In our tertiary care department in Ningbo, China, approximately $94 \%$ of the patients with T2DM had comorbidities, and this influenced the overall management. In a previous study, we found that approximately $72 \%$ of the patients with T2DM were prescribed polypharmacy. ${ }^{22}$ There are no similar studies on comorbidities conducted in patients with T2DM in China published in the English language. However, we found two similar studies published in Mandarin: one on patients with diabetes at a community health centre and another on outpatients with T2DM at a tertiary care hospital..$^{23}{ }^{24}$ The corresponding prevalence figures were around $95 \%$ and $73 \%$, respectively. The different prevalence figures could be explained by the differences in population characteristics, the study setting and the definition of comorbidity applied. Several studies have been conducted on this subject in high-income countries, such as the USA and European countries. ${ }^{25-29}$ All these studies, and also our study, have highlighted the fact that comorbidities are highly prevalent in patients with T2DM. A systematic 
Table 2 Characteristics of the study participants

\begin{tabular}{|c|c|c|c|c|c|}
\hline & $\begin{array}{l}\text { Total } \\
\text { (4777) }\end{array}$ & $\begin{array}{l}\text { Comorbidity } \\
\text { No (299) } \\
\text { n (\%) }\end{array}$ & $\begin{array}{l}\text { Comorbidity } \\
\text { Yes (4478) } \\
\text { n (\%) }\end{array}$ & $\begin{array}{l}\text { Unadjusted OR } \\
(95 \% \mathrm{Cl})\end{array}$ & $P$ value \\
\hline Age (years) & & & & & $<0.001$ \\
\hline 18-39 & 308 & $63(20.5)$ & $245(79.5)$ & 1 & \\
\hline $40-59$ & 1360 & $120(8.8)$ & $1240(91.2)$ & 2.66 (1.90 to 3.71$)$ & \\
\hline $60-69$ & 1289 & $75(5.8)$ & $1214(94.2)$ & 4.16 (2.90 to 5.98$)$ & \\
\hline$\geq 70$ & 1820 & $41(2.3)$ & $1779(97.7)$ & 11.16 (7.37 to 16.90$)$ & \\
\hline Sex & & & & & 0.008 \\
\hline Male & 2482 & $133(5.4)$ & $2349(94.6)$ & 1 & \\
\hline Female & 2295 & $166(7.2)$ & $2129(92.8)$ & 0.73 (0.57 to 0.92$)$ & \\
\hline Education & & & & & 0.005 \\
\hline University/college & 545 & $47(8.6)$ & $498(91.4)$ & 1 & \\
\hline Class $7-12$ & 1927 & $136(7.1)$ & 1791 (92.9) & 1.24 (0.88 to 1.76$)$ & \\
\hline Class 1-6 & 1574 & $80(5.1)$ & $1494(94.9)$ & 1.76 (1.21 to 2.56$)$ & \\
\hline No qualification & 731 & $36(4.9)$ & $695(95.1)$ & 1.82 (1.16 to 2.86$)$ & \\
\hline Occupation & & & & & $<0.001$ \\
\hline Manual worker & 1088 & $74(6.8)$ & $1014(93.2)$ & 1 & \\
\hline Non-manual worker & 1884 & $152(8.1)$ & $1732(91.9)$ & 0.83 (0.62 to 1.10$)$ & \\
\hline Never worked/retired & 1805 & $73(4.0)$ & $1732(96.0)$ & 1.73 (1.24 to 2.41$)$ & \\
\hline Marital status & & & & & 0.008 \\
\hline Married & 4207 & $278(6.6)$ & 3929 (93.4) & 1 & \\
\hline Single/divorced/widowed & 570 & $21(3.7)$ & $549(96.3)$ & 1.85 (1.18 to 2.91$)$ & \\
\hline Residence & & & & & $<0.001$ \\
\hline Urban & 2815 & $145(5.2)$ & $2670(94.8)$ & 1 & \\
\hline Rural & 1962 & $154(7.8)$ & $1808(92.2)$ & 0.64 (0.50 to 0.81$)$ & \\
\hline Health insurance & & & & & $<0.001$ \\
\hline Yes & 4211 & $232(5.5)$ & $3979(94.5)$ & 1 & \\
\hline No & 564 & 67 (11.9) & $497(88.1)$ & 0.43 (0.33 to 0.58$)$ & \\
\hline Smoking (current status) & & & & & 0.073 \\
\hline No & 3714 & $245(6.6)$ & $3469(93.4)$ & 1 & \\
\hline Yes & 1063 & $54(5.1)$ & $1009(94.9)$ & 1.32 (0.98 to 1.79$)$ & \\
\hline Alcohol consumption (current status) & & & & & 0.713 \\
\hline No & 4169 & $263(6.3)$ & $3906(93.7)$ & 1 & \\
\hline Yes & 608 & $36(5.9)$ & $572(94.1)$ & 1.07 (0.75 to 1.53$)$ & \\
\hline Duration of T2DM (years) & & & & & $<0.001$ \\
\hline$\leq 1$ & 981 & $93(9.5)$ & $888(90.5)$ & 1 & \\
\hline$>1-5$ & 880 & $60(6.8)$ & $820(93.2)$ & $1.43(1.02$ to 2.01$)$ & \\
\hline$>5-10$ & 1247 & $74(5.9)$ & $1173(94.1)$ & 1.66 (1.21 to 2.28$)$ & \\
\hline$>10$ & 1669 & $72(4.3)$ & $1597(95.7)$ & 2.32 (1.69 to 3.19$)$ & \\
\hline Blood glucose level (HbA1c) & & & & & 0.458 \\
\hline$<7 \%$ & 899 & $64(7.1)$ & $835(92.9)$ & 1 & \\
\hline$\geq 7 \%$ & 3748 & $226(6.0)$ & $3522(94.0)$ & 1.19 (0.90 to 1.59$)$ & \\
\hline Unknown & 130 & $9(6.9)$ & $121(93.1)$ & 1.03 (0.50 to 2.12 ) & \\
\hline
\end{tabular}

HbA1c, glycated haemoglobin; T2DM, type 2 diabetes mellitus. 
Table 3 Multiple backward stepwise logistic regression analysis for determining factors independently associated with comorbidity

\begin{tabular}{lcc}
\hline & Adjusted OR (95\% Cl) & P value \\
\hline Age (years) & 1 & $<0.001$ \\
\hline $18-39$ & $2.80(1.98$ to 3.96$)$ & \\
$40-59$ & $4.43(3.04$ to 6.44$)$ & \\
$60-69$ & $10.97(7.17$ to 16.77$)$ & \\
$\geq 70$ & & $<0.001$ \\
\hline Sex & 1 & \\
\hline Male & $0.66(0.51$ to 0.84$)$ & \\
\hline Female & 1 & 0.006 \\
\hline Marital status & $1.95(1.21$ to 3.12$)$ & \\
\hline Married & & \\
\hline Single/divorced/widowed & 1 & \\
\hline Residence & 0.018 \\
\hline Urban & $0.75(0.59$ to 0.95$)$ & \\
\hline Rural & & \\
\hline Health insurance & 1 & \\
\hline Yes & $0.62(0.46$ to 0.83$)$ & \\
\hline No & & \\
\hline
\end{tabular}

review and meta-analysis of the prevalence of comorbidities in patients with T2DM in different geographical locations and the factors associated with it will be helpful.

Comorbidities are not synonymous with complications. ${ }^{6}$ In a previous study on the vascular complications of T2DM, we included microvascular complications (ie, diabetic retinopathy, nephropathy and neuropathy/ foot) and macrovascular complications (ie, coronary heart disease, stroke and peripheral arterial disease) and found that more than one-half of the patients with T2DM had vascular complications. ${ }^{30}$ In the present study, we explored comorbidities in patients with T2DM using a recommended definition. Comorbidity was defined as the coexistence of at least one other chronic condition, either a physical (non-communicable/infectious disease) or mental health condition. ${ }^{5-7}$ Unlike the previous study, in the present study, microvascular complications were excluded, as these were consequences of T2DM and should not be considered as comorbidities. ${ }^{6}$ Although HIV infection, tuberculosis and mental health conditions are common comorbidities in patients with T2DM, ${ }^{31-34}$ these were not the most common comorbidities in this study. The prevalences of these infectious diseases are low in Ningbo, ${ }^{35-38}$ and there are chances that mental health conditions were under-reported. It should also be noted that infectious diseases and mental health conditions as index conditions are treated in other specialised hospitals in Ningbo.

We found that the odds of comorbidities increased with age in patients with T2DM. Age is one of the most well-studied and consistent determinants of comorbidities. $^{25} 2839$ Age-related organ degeneration is a natural process and can lead to the development of many health conditions. ${ }^{40}$ However, it should be noted that comorbidities do not correspond with age, and they are not limited to the older population alone. ${ }^{41}$ In our study, the prevalences of comorbidities were around $80 \%$ and $91 \%$ in the 18 to 39 and 40 to 59 years age groups, respectively. We found that the odds of comorbidities were lower in female patients with T2DM compared with those in their male counterparts. This finding is consistent with other studies. ${ }^{2528}$ This could be due to differences at the biological level. Another potential reason could be the reporting differences in sex-specific health conditions. For example, female patients with T2DM often present with atypical symptoms of cardiovascular diseases. ${ }^{42}$ Additionally, the standard non-invasive diagnostic tests perform better in men than in women. ${ }^{43}$ All these hinder the diagnosis of cardiovascular diseases in women. Another example is benign prostatic hyperplasia, one of the most common comorbidities in our study. This comorbidity was diagnosed because of the compulsory ultrasound scan of the urinary system of patients with T2DM at our hospital for possible kidney diseases. In comparison, the gynaecological examination is not a routine examination in women with T2DM.

We found that the odds of comorbidities were lower in patients with T2DM residing in rural areas compared with those in urban areas. This could be due to economic growth, urbanisation and its negative consequences, such as an unhealthy lifestyle. ${ }^{44-46}$ The link between an unhealthy lifestyle and chronic conditions (particularly non-communicable diseases) is well established. ${ }^{47}$ A similar association has also emerged with comorbidities. $^{23} 48$ Another reason could be that rural patients in China have limited access to healthcare and thus, they may undergo fewer diagnostic tests and obtain fewer confirmations of health conditions. ${ }^{49}$ We found that the odds of comorbidities were lower in patients with T2DM without health insurance compared with those with health insurance. This could be due to the fact that over $90 \%$ of the Chinese population have some sort of health insurance, ${ }^{50}$ and these patients may undergo more diagnostic tests (within the scope of their health insurance policy) and obtain confirmation of a range of health conditions. ${ }^{51}$ We found that the odds of comorbidities were higher in single/divorced/widowed patients with T2DM compared with those in married patients. In general, the spouses of married patients provide both physical and mental support to them, and this could help them manage their existing health conditions and prevent new ones from emerging. 5253

This study has several strengths and weaknesses. Comorbidity is a less-explored area in China, and to the best of our knowledge, this was the first study to explore comorbidities in patients with T2DM in Ningbo and the broader Zhejiang Province. The quality of our routinely collected data was good. Unlike other studies where comorbidities in T2DM were self-reported by the patients with T2DM using a predetermined list of 
selected comorbidities, ${ }^{23} 24$ we used a holistic approach. All the conditions were coded using the ICD-10 in our database, and we included all the chronic conditions in our study. This also minimised the possibility of recall bias in our study. Our study had extremely low missing data; only HbA1c data were missing in 130 patients out of 4777 (ie, 2.7\%). Multiple logistic regression analysis included a sample with missing data for the adjusted variable. Since it was a cross-sectional study, the causal relationship between the variables and the comorbidities could not be determined. We propose to conduct a longitudinal study to explore the effects of various factors on comorbidities, including factors considered in this study and other factors, such as physical activity and diet that were not present in our database and could not be adjusted for in the models. In our study, the high prevalence of comorbidities could be due to the study setting (ie, hospital). The findings of our hospital-based study could be valid in similar settings. We suggest conducting a population-based study that might provide a distinct picture of the issue in Ningbo.

In conclusion, we found that a large percentage of patients with T2DM in the tertiary care department in Ningbo, China, had comorbidities, and we also identified the factors associated with comorbidities. The findings could be used in developing, evaluating and implementing interventions aimed at improving outcomes in patients with T2DM with comorbidities.

Acknowledgements The authors thank the patients and Yida Li for the management and organisation of the original data.

Contributors $\mathrm{JL}$ and $\mathrm{KC}$ designed the study. $\mathrm{XL}$ and $\mathrm{KC}$ analysed the data and wrote the first draft of the manuscript. SX and $Y C$ contributed to patient registration and data entry. XL contributed to data cleaning. XL, KC, SX, YC, MX, LL and JL revised it critically for important intellectual content and approved the final version.

Funding The work was supported by the Medical Health Science and Technology Project of Zhejiang Province (Grant No. 2019KY562) and the Major Program of Social Development of Ningbo Science and Technology Bureau (Grant No. 2019C50094).

\section{Competing interests None declared.}

Patient and public involvement Patients and/or the public were not involved in the design, or conduct, or reporting, or dissemination plans of this research.

Patient consent for publication Not required.

Ethics approval The Research Ethics Committee of Ningbo First Hospital, China, approved the study (2020-R106).

Provenance and peer review Not commissioned; externally peer reviewed.

Data availability statement Data are available upon reasonable request. The data set will be available upon request unless there are legal or ethical reasons for not doing so.

Open access This is an open access article distributed in accordance with the Creative Commons Attribution Non Commercial (CC BY-NC 4.0) license, which permits others to distribute, remix, adapt, build upon this work non-commercially, and license their derivative works on different terms, provided the original work is properly cited, appropriate credit is given, any changes made indicated, and the use is non-commercial. See: http://creativecommons.org/licenses/by-nc/4.0/.

\section{ORCID iDs}

Kaushik Chattopadhyay http://orcid.org/0000-0002-3235-8168

Li Li http://orcid.org/0000-0001-6301-3544

Jialin Li http://orcid.org/0000-0001-6930-9530
REFERENCES

1 Ningbo Municipal Statistics Bureau. Statistical Bulletin on national economic and social development in Ningbo, China, 2018.

2 Health and Family Planning Commission of Ningbo Municipality. Prevention and treatment of chronic diseases in Ningbo. Available: http://www.cnnb.com.cn/nbzfxwfbh/system/2014/05/22/008068694. shtml [Accessed 25 Apr 2020].

3 Yao DZ, Sun XH, JH L. Prevalence and risk factors of diabetes in people over 40 years of age in Ningbo City area. Modern Pract Med 2016;28:1343-5.

4 Li H, Cui J, Gong J, et al. Diabetes morbidity and mortality of residents in Ningbo, 2010-2014. Chinese Rural Health Service Administration 2016;36:1304-7.

5 World Health Organization. Multimorbidity. Geneva, Switzerland: World Health Organization, 2016.

6 Ording AG, Sørensen HT. Concepts of comorbidities, multiple morbidities, complications, and their clinical epidemiologic analogs. Clin Epidemiol 2013;5:199-203.

7 Valderas JM, Starfield B, Sibbald B, et al. Defining comorbidity: implications for understanding health and health services. Ann Fam Med 2009;7:357-63.

8 Einarson TR, Acs A, Ludwig C, et al. Prevalence of cardiovascular disease in type 2 diabetes: a systematic literature review of scientific evidence from across the world in 2007-2017. Cardiovasc Diabetol 2018;17:83.

9 Nouwen A, Winkley K, Twisk J, et al. Type 2 diabetes mellitus as a risk factor for the onset of depression: a systematic review and metaanalysis. Diabetologia 2010;53:2480-6.

10 Yokomichi H, Nagai A, Hirata M, et al. Survival of macrovascular disease, chronic kidney disease, chronic respiratory disease, cancer and smoking in patients with type 2 diabetes: Biobank Japan cohort. J Epidemiol 2017;27:S98-106.

11 Adriaanse MC, Drewes HW, van der Heide I, et al. The impact of comorbid chronic conditions on quality of life in type 2 diabetes patients. Qual Life Res 2016;25:175-82.

12 Wermeling PR, Gorter KJ, van Stel HF, et al. Both cardiovascular and non-cardiovascular comorbidity are related to health status in well-controlled type 2 diabetes patients: a cross-sectional analysis. Cardiovasc Diabetol 2012;11:121.

13 Gruneir A, Markle-Reid M, Fisher K, et al. Comorbidity burden and health services use in community-living older adults with diabetes mellitus: a retrospective cohort study. Can J Diabetes 2016;40:35-42.

14 Terauchi Y, Ozaki A, Zhao X, et al. Humanistic and economic burden of cardiovascular disease related comorbidities and hypoglycaemia among patients with type 2 diabetes in Japan. Diabetes Res Clin Pract 2019;149:115-25.

15 Australian Bureau of Statistics. National health survey: first result, 2014-15. Canberra, Australian: Australian Bureau of Statistics, 2015.

16 Druss BG, Marcus SC, Olfson M, et al. Comparing the National economic burden of five chronic conditions. Health Aff 2001;20:233-41.

17 Ningbo First Hospital. Hospital introduction. Available: http://www. nbdyyy.com/col/col100/index.html [Accessed 25 Apr 2020].

18 Ministry of Health of the People's Republic of China. The measures for the administration of the hospital grade. Beijing: Ministry of Health of the People's Republic of China, 1989.

19 Chinese Diabetes Society. China guideline for type 2 diabetes (2010 ed). Chin J Diabetes 2012;20:S1-36.

20 Chinese Diabetes Society. China guideline for type 2 diabetes (2013 ed). Chin J Endocrinol Metab 2014;30:893-942.

21 Jia W, Weng J, Zhu D, et al. Standards of medical care for type 2 diabetes in China 2019. Diabetes Metab Res Rev 2019;35:e3158.

22 Li J, Chattopadhyay K, Xu M, et al. Prevalence and predictors of polypharmacy prescription among type 2 diabetes patients at a tertiary care department in Ningbo, China: a retrospective database study. PLoS One 2019;14:e0220047.

23 Xing Y, Wang P, Yang X. A survey of comorbidity and health behaviors of diabetic patients in an area of Beijing. $J$ Chin Phys 2020;22:379-84.

24 Zhao W, Zhao D, Wang X, et al. Current status and influential factors of co-morbidity for patients with type 2 diabetes mellitus in Tongzhou district of Beijing. Chin J Health Manage 2019;13:541-5.

25 Alonso-Morán E, Orueta JF, Esteban JIF, et al. Multimorbidity in people with type 2 diabetes in the Basque country (Spain): prevalence, comorbidity clusters and comparison with other chronic patients. Eur J Intern Med 2015;26:197-202.

26 Lin P-J, Kent DM, Winn A, et al. Multiple chronic conditions in type 2 diabetes mellitus: prevalence and consequences. Am J Manag Care 2015;21:e23-34.

27 Teljeur C, Smith SM, Paul G, et al. Multimorbidity in a cohort of patients with type 2 diabetes. Eur J Gen Pract 2013;19:17-22. 
28 Iglay K, Hannachi H, Joseph Howie P, et al. Prevalence and coprevalence of comorbidities among patients with type 2 diabetes mellitus. Curr Med Res Opin 2016;32:1243-52.

29 Hermans MP, Dath N. Prevalence and co-prevalence of comorbidities in Belgian patients with type 2 diabetes mellitus: a transversal, descriptive study. Acta Clin Belg 2018;73:68-74.

$30 \mathrm{Li}$ J, Chattopadhyay K, Xu M, et al. Prevalence and associated factors of vascular complications among inpatients with type 2 diabetes: a retrospective database study at a tertiary care department, Ningbo, China. PLoS One 2020;15:e0235161.

31 Workneh MH, Bjune GA, Yimer SA. Prevalence and associated factors of tuberculosis and diabetes mellitus comorbidity: a systematic review. PLoS One 2017;12:e0175925.

32 Berkowitz N, Okorie A, Goliath R, et al. The prevalence and determinants of active tuberculosis among diabetes patients in Cape town, South Africa, a high HIV/TB burden setting. Diabetes Res Clin Pract 2018;138:16-25.

33 Hadigan C, Kattakuzhy S. Diabetes mellitus type 2 and abnormal glucose metabolism in the setting of human immunodeficiency virus. Endocrinol Metab Clin North Am 2014;43:685-96.

34 Garrett C, Doherty A. Diabetes and mental health. Clin Med 2014;14:669-72.

35 Yang T, Chen T, Che Y, et al. Factors associated with catastrophic total costs due to tuberculosis under a designated hospital service model: a cross-sectional study in China. BMC Public Health 2020;20:1009.

36 Liu K, Li T, Vongpradith A, et al. Identification and prediction of tuberculosis in eastern China: analyses from 10-year populationbased notification data in Zhejiang Province, China. Sci Rep 2020;10:7425.

37 Zhang JH, Li HL, Shi HB, et al. [Survival analysis of HIV/AIDS patients with access to highly antiretroviral therapy in Ningbo during 2004-2015]. Zhonghua Liu Xing Bing Xue Za Zhi 2016;37:1262-7.

38 Ministry of Health of the People's Republic of China, UNAIDS, WHO. Estimation for HIV/AIDS epidemic trend in 2011, China. Chin J AIDS STD 2012;18:1-5.

39 Mata-Cases M, Franch-Nadal J, Real J, et al. Prevalence and coprevalence of chronic comorbid conditions in patients with type 2 diabetes in Catalonia: a population-based cross-sectional study. BMJ Open 2019;9:e031281.

40 King M, Lipsky MS. Clinical implications of aging. Dis Mon 2015;61:467-74.
41 van Oostrom SH, Gijsen R, Stirbu I, et al. Time trends in prevalence of chronic diseases and multimorbidity not only due to aging: data from general practices and health surveys. PLoS One 2016;11:e0160264.

42 Wada H, Miyauchi K, Daida H. Gender differences in the clinical features and outcomes of patients with coronary artery disease. Expert Rev Cardiovasc Ther 2019;17:127-33.

43 Shah ASV, Griffiths M, Lee KK, et al. High sensitivity cardiac troponin and the under-diagnosis of myocardial infarction in women: prospective cohort study. BMJ 2015;350:g7873.

44 Zhu W, Chi A, Sun Y. Physical activity among older Chinese adults living in urban and rural areas: a review. J Sport Health Sci 2016;5:281-6.

45 Muntner P, Gu D, Wildman RP, et al. Prevalence of physical activity among Chinese adults: results from the International collaborative study of cardiovascular disease in Asia. Am J Public Health 2005:95:1631-6.

46 Miao J, Wu X. Urbanization, socioeconomic status and health disparity in China. Health Place 2016;42:87-95.

47 World Health Organization. Global action plan for the prevention and control of NCD 2013-2020. Geneva: Switzerland, 2013.

48 Wang X, Chen J, Liu X, et al. Identifying patterns of lifestyle behaviors among people with type 2 diabetes in Tianjin, China: a latent class analysis. Diabetes Ther 2017;8:1379-92.

49 Liu Z, Albanese E, Li S, et al. Chronic disease prevalence and care among the elderly in urban and rural Beijing, China - a 10/66 Dementia Research Group cross-sectional survey. BMC Public Health 2009;9:394.

50 Zhao C, Wang C, Shen C, et al. China's achievements and challenges in improving health insurance coverage. Drug Discov Ther 2018:12:1-6.

51 Yang C, Huang Z, Sun K, et al. Comparing the economic burden of type 2 diabetes mellitus patients with and without medical insurance: a cross-sectional study in China. Med Sci Monit 2018;24:3098-102.

52 Stroebe M, Schut H, Stroebe W. Health outcomes of bereavement. Lancet 2007;370:1960-73.

53 Parajuli J, Saleh F, Thapa N, et al. Factors associated with nonadherence to diet and physical activity among Nepalese type 2 diabetes patients; a cross sectional study. BMC Res Notes $2014 ; 7: 758$ 